\title{
Cyanide intoxication in the rat: physiological and neuropathological aspects
}

\author{
J. B. BRIERLEY ${ }^{1}$, A. W. BROWN, AND JANE CALVERLEY \\ From the Medical Research Council Laboratories, Carshalton, Surrey
}

SYNOPSIS Sodium cyanide was given to rats by intravenous infusion at a rate that would avert apnoea (the first sign of overdosage) in the majority. There was full physiological monitoring in a group under anaesthesia and more limited monitoring in an unanaesthetized group. White matter was damaged in six animals and grey matter additionally in only one. It was concluded that cyanide can damage neurones only through the medium of secondary effects on circulation and respiration.

Numerous experimental studies have shown that intoxication by cyanide compounds can lead to damage in the brains of rats, rabbits, cats, dogs, and monkeys (see reviews by Levine and Stypulkowski, 1959; Meyer, 1963).

It is now evident that, where their physiological and neuropathological effects are concerned, there are no differences between cyanide compounds and that the cyanide ion is the common toxic agent. It is also evident that damage in the grey and white matter of the nervous system can follow a single administration of cyanide by subcutaneous, intramuscular, intravenous, or respiratory routes (Levine and Wenk, 1959; Levine and Stypulkowski, 1959).

While brain damage in the experimental animal is usually regarded as an instance of histotoxic hypoxia due to the inhibition of neuronal cytochrome oxidase, no experimental study has convincingly excluded the additional contributions of secondary respiratory and cardiovascular changes. Thus, the ability of cyanide, per se, to damage the nerve cells of the central nervous system remains unproven. Even so, it has been stated by Van Liere and Stickney (1963) that 'narcotics, anaesthetic agents and certain other compounds may produce histotoxic hypoxia, but nearly all these produce undesirable side effects; there are few agents, if any, outside of the cyanides, which 1 Address for reprint requests: J. B. Brierley, M.R.C. Laboratories,
Woodmansterne Road, Carshalton, Surrey, U.K.

(Accepted 5 September 1975.) produce unequivocal histotoxic hypoxia' (p. 28).

The purpose of the present study was to determine whether uncomplicated cyanide intoxication could cause damage in the rat brain and particularly in neurones. If so, it would be apparent whether a pure histotoxic hypoxia produced irreversible structural alterations only within those regions already known to be selectively vulnerable to hypoxia of all other types (Meyer, 1963; Brierley, 1973), in every neurone of the central nervous system, or within some different pattern.

The investigation, in the rat, is divided into three parts,

1. As slowing of respiration leading to apnoea is the first sign of cyanide overdosage, it was necessary to determine the rate of intravenous infusion of a standard solution of sodium cyanide which, when adjusted for body weight, would just avert apnoea in a majority of eight animals.

2. The standard solution of cyanide was infused initially at this rate, intravenously, into 11 lightly anaesthetized animals. The principal criteria of cardiovascular and respiratory functions were recorded, as well as the electromyogram (EMG) and the electroencephalogram (EEG).

3. The standard solution of cyanide was infused intravenously into eight unanaesthetized, restrained animals with recording of only the respiratory rate and depth, the EMG, the electrocardiogram (ECG), and the EEG. 
In the animals of groups 2 and 3 the brains were submitted to full neuropathological examination after in vivo perfusion-fixation so that observed brain damage could be correlated, not only with a particular physiological status as defined by the parameters recorded, but also with observed behaviour during the recovery period. In these two groups, brain damage was infrequent and involved grey matter in only one animal. In all animals exhibiting neuropathological alterations there were considerable and complex secondary effects involving respiratory and cardiovascular functions.

\section{METHODS}

Levine and Wenk (1959) have shown that a single intravenous injection of potassium cyanide $(0.65-$ $2.43 \mathrm{mg}$; average $1.65 \mathrm{mg}$ ) over a period of $28-62$ minutes produced brain damage in rats $(250 \mathrm{~g}$ body weight). As the concentration of the cyanide was $0.01-0.05 \%$, the volumes injected must have been at least $5 \mathrm{ml}$-that is, $2.0 \mathrm{ml} / 100 \mathrm{~g}$ body weight. In the present study, a concentration of sodium cyanide of $0.2 \%$ was chosen, so that the maximum volume injected was under $1.0 \mathrm{ml} / 100 \mathrm{~g}$ in all.

The animals of all three groups received a solution of $0.2 \%$ sodium cyanide in physiological saline, neutralized with $0.15 \mathrm{M}$ citric acid. In each animal, the solution of cyanide was infused into a tail vein using a Palmer variable speed injection apparatus.

Slowing of respiration leading to apnoea is the first indication of cyanide overdosage. In rats (250-290 g body weight), preliminary experiments showed that, if the standard solution of sodium cyanide was infused at a rate of $0.0903 \mathrm{mg} / \mathrm{min}$, apnoea did not occur before 20 minutes. In the animals of group 1 the infusion of cyanide was begun at this rate.

GROUP 1, EIGHT ANIMALS Eight white Wistar rats (Carshalton strain) of both sexes, weight range $220-450 \mathrm{~g}$ (mean $320 \mathrm{~g}$ ) were used. Anaesthesia was induced by the intraperitoneal injection of pentobarbitone $(2.4 \mathrm{mg} / 100 \mathrm{~g}$ body weight).

After tracheostomy and the insertion of a polyethylene tube, a tail vein was cannulated with the shaft of a No. 15 needle connected by an appropriate cannula to a syringe containing heparin in saline $(1,000 \mathrm{IU} / \mathrm{ml})$ which was injected intermittently until the start of cyanide infusion.

Respiration was recorded continuously from a water-filled coil of soft rubber tubing around the thorax, connected to a pressure transducer (Statham P 23. BC).
The ECG was recorded from subcutaneous electrodes (left forepaw and left chest) and the EEG from two parietal scalp needle electrodes.

Respiration, ECG, and EEG were recorded continuously on a Grass 4 channel Dynograph (Model $5 b)$.

In each animal of this group the dose of sodium cyanide was expressed as $\mathrm{mg} / \mathrm{min} / 100 \mathrm{~g}$ body weight.

GROUP 2, 11 ANIMALS Eleven rats, weight range 400-500 g (mean $485 \mathrm{~g}$ ) were used. Anaesthesia, tracheostomy, cannulation of a tail vein, and the recording of respiration, ECG, and EEG were carried out as in the animals of group 1. In addition, the tail artery was cannulated (PP 30 polyethylene cannula, Portex, Hythe, Kent, U.K.) for the continuous recording of blood pressure with an Elcomatic EM 750 pressure transducer. The EMG was recorded on the Dynograph from a pair of electrodes in the muscles of one shoulder girdle. Blood samples $(150 \mu \mathrm{l})$ were drawn intermittently from the arterial cannula into heparinized capillary tubes and oxygen tension was measured with a Clark-type electrode (E 5046), carbon dioxide with a Severinghaus-type

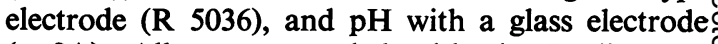
(g 2A). All were recorded with the Radiometer (Copenhagen) Blood Microsystem.

GROUP 3, EIGHT ANIMALS Eight rats, weight range, $330-480 \mathrm{~g}$ (mean $405 \mathrm{~g}$ ) were anaesthetized with intraperitoneal pentobarbitone $(2.4 \mathrm{mg} / 100 \mathrm{~g}$ body weight) for cannulation of the tail vein, insertion of the ECG, EMG, and EEG electrodes and the application of the tube to record respiration. The animals were then placed in a cylindrical restraining cage (Stoner, 1971) within which they could not turn round but which did not interfere with respiration before and after consciousness had been regained.

At the end of a chosen survival period (measured from the start of cyanide infusion) or if cardiorespiratory collapse seemed imminent, the animals of groups 2 and 3 were deeply anaesthetized with pentobarbitone via the tail vein and heparin (250 IU/100 $\mathrm{g}$ body weight) was injected by the same route.

In vivo perfusion-fixation of the nervous system was then carried out, as described by Brown and Brierley (1968), using FAM (formaldehyde, glacial acetic acid, absolute methanol; $1: 1: 8)$ after a brief washout with physiological saline. The brain was left in situ at room temperature for two hours before its removal and storage in fixative at $4^{\circ} \mathrm{C}$ overnight. The forebrain was cut coronally and two slices, each $3 \mathrm{~mm}$ thick and sited anterior and posterior to an initial cut through the pituitary stalk, together with a paramedian block including brain-stem and cerebel- 
lum, were embedded in paraffin. Sections cut at 7 and $12 \mu \mathrm{m}$ were stained with cresyl violet, cresyl violet and luxol fast blue, and with haematoxylin and eosin.

\section{RESULTS}

GROUP 1, EIGHT ANIMALS The first five animals (Table 1) received the standard sodium cyanide solution, intravenously, at the rate of 0.0903 $\mathrm{mg} / \mathrm{min}$ without interruption until apnoea occurred, when the infusion was terminated.

TABLE 1

GROUP 1 (EIGHT ANIMALS-ANAESTHETIZED)

\begin{tabular}{|c|c|c|c|c|c|}
\hline \multirow[t]{2}{*}{ No. } & \multirow{2}{*}{$\begin{array}{l}\text { Body wt. } \\
\quad(g)\end{array}$} & \multirow{2}{*}{$\begin{array}{l}\text { Total } \\
\mathrm{NaCn} \\
\text { (mg) }\end{array}$} & \multicolumn{2}{|c|}{ Duration (min) } & \multirow{2}{*}{$\begin{array}{l}\text { Rate of infusion } \\
(\mathrm{mg} / \mathrm{min} / 100 \mathrm{~g})\end{array}$} \\
\hline & & & $\begin{array}{c}\text { NaCn } \\
\text { infusion }\end{array}$ & $\begin{array}{l}\text { Inter- } \\
\text { ruptions } \\
\text { (and } \\
\text { number) }\end{array}$ & \\
\hline 1 & 250 & 1.8 & 21 & 0 & 0.0343 \\
\hline 2 & 255 & 3.0 & 32 & 0 & 0.0368 \\
\hline 3 & 280 & 2.4 & 27 & 0 & 0.0318 \\
\hline 4 & 290 & 1.8 & 25 & 0 & 0.0248 \\
\hline 5 & 250 & 1.6 & 20 & 0 & 0.0320 \\
\hline 6 & 220 & 3.3 & 36 & $21 \frac{1}{2}(2)$ & 0.0404 \\
\hline 7 & 260 & 2.6 & 39 & 17 (2) & 0.0256 \\
\hline 8 & 450 & 5.7 & 81 & $19(3)$ & 0.0154 \\
\hline
\end{tabular}

Control respiratory rates were $56-126 / \mathrm{min}$. In three animals (nos. 2, 3, and 4) the respiratory rate rose by $30-100 \%$, nine to 12 minutes after the start of cyanide infusion and then decreased. In animals nos. 1 and 5 respiratory rate decreased from the outset. Apnoea occurred in all five at 20 to 32 minutes from the start of cyanide infusion and mechanical ventilation had to be maintained until death from cardiac failure three to 32 minutes later. Control heart rates were in the range $384-492 / \mathrm{min}$. In three animals there was a progressive moderate bradycardia and in nos. 1 and 5 a sustained marked tachycardia. Epileptic spike and wave activity in the EEG was seen in all five animals eight to 28 minutes after the start of cyanide infusion. In each animal one or more grand mal epileptic seizures occurred and the EEG became isoelectric or near-isoelectric 15 to 30 minutes after the start of the infusion and showed no recovery.
In these five animals the cyanide dose was $0.0248-0.0368 \mathrm{mg} / \mathrm{min} / 100 \mathrm{~g}$.

In the remaining three animals (Table 1$)$ the initial infusion rate of cyanide $(0.0903 \mathrm{mg} / \mathrm{min})$ was sooner or later reduced and/or briefly interrupted in order to minimize or avert secondary cardiorespiratory effects.

In animal no. 6 respiratory rate fell after a brief initial rise and apnoea occurred at 17 minutes. There were minor alterations in heart rate throughout. The first epileptic seizure occurred at 18 minutes and spontaneous respiration recommenced at 21 minutes. The resumption of modified and interrupted infusions of cyanide led to six further periods of apnoea with corresponding periods of mechanical ventilation of up to four minutes' duration. After the last cessation of respiration (at 63 minutes) cyanide infusion was terminated, the EEG became isoelectric and did not recover. Mechanical ventilation was continued until death from cardiac failure 95 minutes from the start of cyanide infusion. The rate of cyanide infusion was calculated from the total amount of cyanide (mg), the duration of infusion (excluding interruptions), and the body weight-that is, $0.0404 \mathrm{mg} / \mathrm{min} / 100 \mathrm{~g}$.

In animal no. 7 a marked early increase in respiratory rate and depth was followed by a fall in rate, and apnoea occurred at 26 minutes and lasted $2 \frac{3}{4}$ minutes. There were minor fluctuations in heart rate before a progressive fall. Several bursts of spike and wave activity in the EEG preceded a seizure at 27 minutes after which the EEG was isoelectric for about $2 \frac{1}{2}$ minutes. Resumption of the infusion of cyanide led to two further brief periods of apnoea and corresponding brief periods of isoelectric EEG. The EEG then recovered and respiratory and cardiac rates returned to normal until the animal was killed deliberately 90 minutes after the termination of cyanide infusion. The rate of cyanide infusion was $0.0256 \mathrm{mg} / \mathrm{min} / 100 \mathrm{~g}$.

In animal no. 8 respiratory rate rose by about $30 \%$ within three minutes and was maintained for about 60 minutes by modifying and very briefly interrupting the infusion of cyanide. A slight fall in respiratory rate preceded a one minute period of apnoea at 75 minutes. Heart rate had fallen only slightly. Several spike and wave complexes led up to the first grand mal 
TABLE 2

GROUP 2 (11 ANIMALS-ANAESTHETIZED)

\begin{tabular}{|c|c|c|c|c|c|c|}
\hline \multirow[t]{2}{*}{ No. } & \multicolumn{2}{|c|}{ EEG near-isoelectric periods } & \multirow{2}{*}{$\begin{array}{c}G M \\
\text { seizures }\end{array}$} & \multirow{2}{*}{$\begin{array}{c}\text { Spike } \\
\text { and wate }\end{array}$} & \multirow{2}{*}{$\begin{array}{l}\text { Surrital } \\
\qquad(h)\end{array}$} & \multirow[t]{2}{*}{ Apnoea } \\
\hline & $\begin{array}{c}\text { Onset at } \\
(\text { min })\end{array}$ & $\begin{array}{l}\text { Total duration } \\
\text { (and number) }\end{array}$ & & & & \\
\hline 1 & - & - & 3 & +++ & 4 & - \\
\hline 2 & - & - & 3 & 0 & $4 !$ & - \\
\hline 3 & - & - & 2 & + & $4 \frac{1}{2}$ & - \\
\hline 4 & 55 & $2(1)$ & 0 & ++ & 3 & $\ldots$ \\
\hline $5 *$ & 45 & $15(1)$ & 3 & + & 28 & A \\
\hline 6 & - & - & 2 & + & 23 & - \\
\hline 7* & 75 & $35(2)$ & 5 & $++t$ & 31 & $\mathbf{A}$ \\
\hline $8^{*}$ & 55 & $25(2)$ & 4 & +++ & 29 & - \\
\hline 9 & 90 & $25(2)$ & 4 & +++ & 29 & - \\
\hline 10 & 95 & $10(2)$ & 3 & ++ & 28 & - \\
\hline $11^{*+}$ & 70 & $19(3)$ & 4 & +++ & 27 & A \\
\hline
\end{tabular}

The occurrence of near isoelectric periods in the EEG, grand mal seizures, spike and wave activity, and apnoea. Survival is measured from ${ }^{-}$the start of cyanide infusion.

* = brain damage- white matter.

$\dagger=$ brain damage - grey matter.

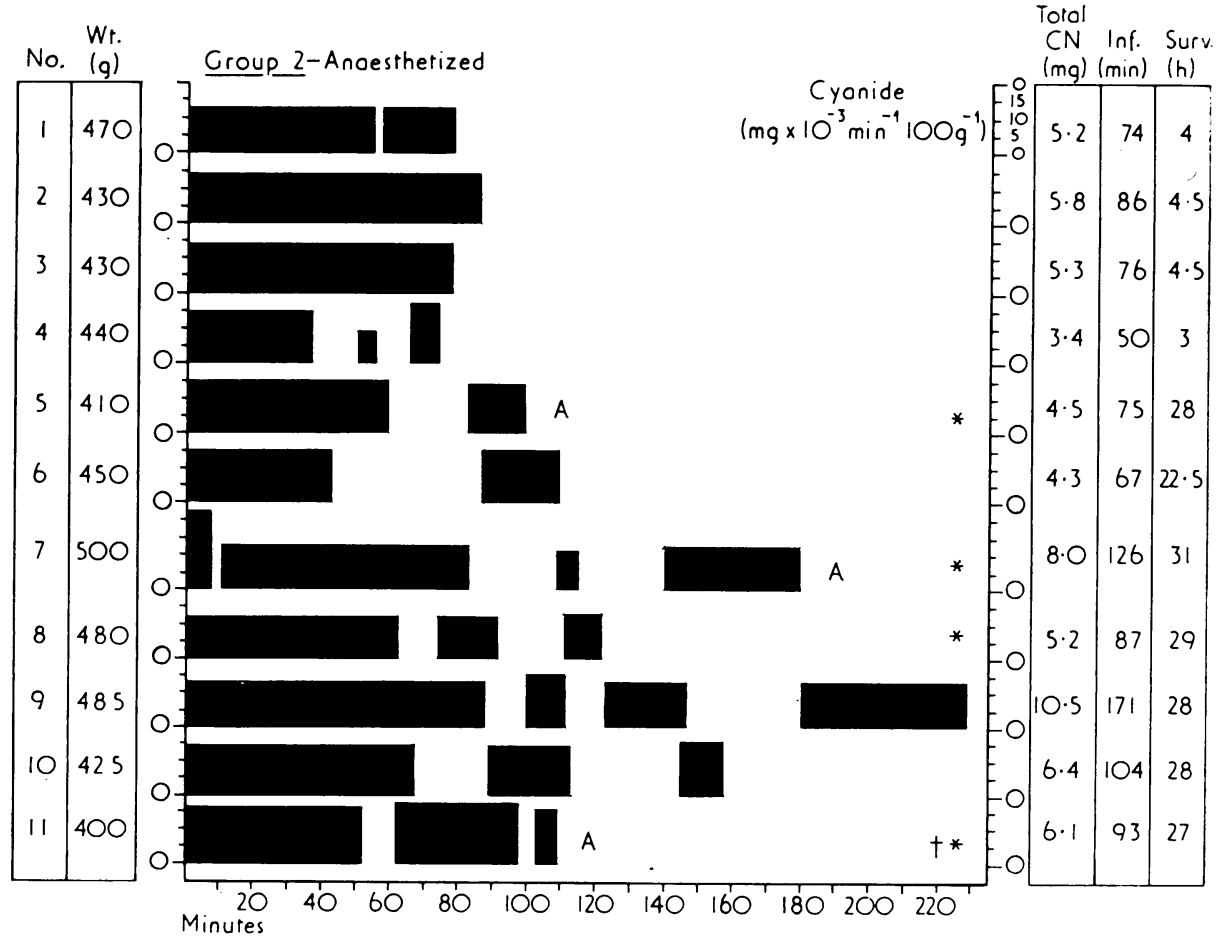

FIG. 1, Group 2. Showing body weights, rates of cyanide infusion, total cyanide dose $(\mathrm{mg})$, total infusion time $(\mathrm{min})$, survival $(h)$, incidence of apnoea $(A)$ and of brain damage. $*=$ White matter damage $;+=$ neuronal damage. 
seizure at 15 minutes. Further complexes and three seizures occurred before the EEG became isoelectric at 75 minutes for about one minute. High voltage slow waves were present up to about 88 minutes when an isoelectric period of about 0.5 minutes coincided with apnoea of the same duration. Cyanide infusion was then stopped, there was no further epileptic activity, the EEG returned to normal and the respiratory and heart rates returned to their normal levels. The animal was killed $1 \frac{1}{2}$ hours after the end of the cyanide infusion. The rate of cyanide infusion was $0.0154 \mathrm{mg} / \mathrm{min} / 100 \mathrm{~g}$.

As the two episodes of apnoea in this animal were brief (1.0 and $0.5 \mathrm{~min}$ ), it was concluded that, if the dose of cyanide were reduced by $10 \%$, apnoea would probably be averted in the majority of animals. Thus, cyanide was infused initially in the animals of groups 2 and 3 at a rate of $0.014 \mathrm{mg} / \mathrm{min} / 100 \mathrm{~g}$.

GROUP 2, 11 ANIMALS The body weights, periods and rates of cyanide infusion, total dose of cyanide and the incidence of apnoea, and of brain damage are given in Fig. 1.

Epileptic activity and the EEG In seven of the 11 animals (Table 2) (nos. 4, 5, 7, 8, 9, 10, 11), the EEG was reduced to a near-isoelectric state on one to three occasions. This assessment was made with an awareness of unavoidable cardiac and respiratory elements in the recordings. The near-isoelectric state was reached 45 to 95 minutes after the start of cyanide infusion and lasted two to 35 minutes.

In every animal, the early alterations in the EEG consisted of a reduction in voltage followed by a diminution in fast activity. Slow waves of variable voltage then appeared and in 10 of the 11 animals were followed by epileptic spike and wave activity and two to five grand mal seizures were then observed. These usually lasted from five to 20 seconds but occasionally took the form of status epilepticus lasting up to 90 seconds. When epileptic seizures were frequent, and particularly in animals 9 and 11 , it was not always possible to distinguish overt epileptic activity from the myoclonus due to tetany.

In every animal, the EEG showed evidence of recovery 10 to 15 minutes after the termination of cyanide infusion. The follow-up EEG was abnormal in animals 5 and 11 , recorded after 27 and 25 hours respectively. In each, there was a marked reduction in fast activity, high voltage slow waves were prominent but there was no evidence of epileptic activity.

Respiration From a mean control rate of $60 / \mathrm{min}$ (range, $48-78 / \mathrm{min}$ ) respiratory rate increased by a mean of $104 \%$ (range, $45-228 \%$ ). The maximal values occurred after a mean interval of 33 minutes (range, 15 to 65 minutes) from the start of cyanide infusion.

The depth of respiration as measured by the pen excursion increased by approximately twofold in four animals and fourfold in the other seven.

In 10 animals an increased respiratory rate (mean $103 \%$ : range $41-208 \%$ ) was maintained for some period after the end of cyanide infusion. Peak respiratory rates were recorded 16 to 179 minutes (mean 75 minutes) after the last infusion of cyanide. In three animals (nos. 1, 2, and 3) respiratory rate was still increased by $41 \%, 108 \%$, and $60 \%, 162,157$ and $179 \mathrm{~min}-$ utes respectively after the end of cyanide infusion.

Brief apnoea occurred in three animals (nos. 5,7 , and 11) at the end of the last period of cyanide infusion (Fig. 1) and mechanical ventilation was required for five to 30 seconds.

Arterial gas tensions and $p H$ The mean control oxygen tension $\left(\mathrm{a} . \mathrm{pO}_{2}\right.$ ) was $85 \mathrm{mmHg}$ (range, 65-115 mmHg). In each animal a. $\mathrm{pO}_{2}$ increased and the mean maximum recorded value was $125 \mathrm{mmHg}$ (range, $90-140 \mathrm{mmHg}$ ). Maximal values occurred 15 to 110 minutes after the start of cyanide infusion-that is, within 15 to 55 minutes in three animals; within 70 to 80 minutes in four animals and within 95 to 110 minutes in four animals.

The mean control arterial carbon dioxide tension (a.pCO $\mathrm{pO}_{2}$ ) was $50 \mathrm{mmHg}$ (range $45-$ $65 \mathrm{mmHg}$ ). In each animal a. $\mathrm{pCO}_{2}$ decreased to a mean minimum value of $15 \mathrm{mmHg}$ (range, 10-20 mmHg). Minimal values occurred at 33 to 115 minutes after the start of cyanide infusion. They occurred after 33 to 35 minutes in two animals, after 56 to 80 minutes in six animals and after 81 to 115 minutes in three 
animals. In nine animals in which blood samples were taken after the end of cyanide infusion a.pCO $\mathrm{CO}_{2}$ did not return to normal. This included a sample taken after 170 minutes in animal no. 17.

The mean control arterial pH (a.pH) was 7.394 (range, 7.295-7.512). In each animal a.pH increased to a mean maximum of 7.613 (range, 7.441-7.769). These maximal values occurred 15 to 73 minutes after the start of cyanide infusion-that is, within 15 to 30 minutes in two animals; within 31 to 50 minutes in five animals, and within 51 to 73 minutes in four animals. The a.pH then began to fall. In three animals (nos. 1, 3,6 ) it did not fall below the control level. In the other eight animals a.pH fell by $0.04-0.49 \mathrm{pH}$ units below control levels. The greatest fall occurred in no. 11.

In six animals (nos. $3,5,6,7,8,10$ ) the arterial $\mathrm{pH}$ rose again. This rise was first seen 35 minutes after the end of cyanide infusion in animal no. 10 .

Tetany Tetany was seen, palpated, and recorded in the EMG in all 11 animals for periods of 10 to 65 minutes-that is, for 10 to $15 \mathrm{~min}$ utes in three animals (nos. 5, 6, 10) and for 35 to 65 minutes in the remaining eight animals (nos. $1,2,3,4,7,8,9,11$ ). In four animals (nos. 5, 6, $7,8)$ the overall period of tetany included a second phase as a consequence of a subsequent infusion of cyanide. In eight animals (nos. 1, 2, $3,6,8,9,10,11)$ the uniform electromyogram characteristic of tetany was interrupted by high voltage waves occurring singly or in groups. These were the counterparts of overt myoclonus in the muscles of fore and/or hind limbs. In two animals (nos. 9 and 11) virtually the whole body musculature seemed to be involved in myoclonic activity.

With the qualification that, in any one animal, the number of blood samples taken was relatively small and that the onset of tetany could not be defined with precision, the maximum a.pH seemed to be more or less coincident with the onset of tetany in seven animals, just before it in two animals and just after it in two animals.

Mean arterial blood pressure and heart rate The mean control arterial blood pressure-that is, diastolic pressure $+\frac{1}{3}$ pulse pressure-was $112 \mathrm{mmHg}$ (range, $100-135 \mathrm{mmHg}$ ).

At 15 to 50 minutes after the start of cyanide infusion mean arterial blood pressure had fallen by a mean of $64 \%$ (range, $30 \%-84 \%$ )-that is, by $30 \%$ after 20 minutes in one animal (no. 2); by $55-70 \%$ after 15 to 40 minutes in six animals (nos. $1,5,6,7,8,10$ ) and by $77-84 \%$ after 15 to 50 minutes in four animals (nos. 3, 4, 9, 11).

The range of control heart rates was 290 $445 / \mathrm{min}$. In one animal (no. 4) the heart rate fell steadily and was $10 \%$ below control level at the time of maximum hypotension. In another animal (no. 11) hypotension was not accompanied by significant alteration in heart rate. In the remaining nine animals heart rates had risen by $10-38 \%$ of control values at about the end of the initial hypotension. In all animals, at this time, there was no consistent relationship between heart rate and mean arterial blood pressure.

After the initial arterial hypotension, grand mal seizures were usually accompanied by a sharp rise in blood pressure (maximum systolic blood pressure $155 \mathrm{mmHg}$ in no. 10). In 10 animals there was a gradual increase in theo interictal blood pressure but in one (no. 4) the initial fall in mean blood pressure was pro gressive until perfusion-fixation was carried out at $1 \frac{3}{4} \mathrm{~h}$ when an abrupt bradycardia heralded cardiac failure. In three animals (nos. $1,2,3$ ) the initial hypotension was followed by two or three grand mal seizures with corresponding hypertension. The blood pressure then returned to normal levels until perfusion-fixation was carried out at three hours from the start of cyanide infusion.

In five of the remaining seven animals there was a fall in mean blood pressure (to 30-50 $\mathrm{mmHg}$ ) and in heart rate at or near the termination of the first period of cyanide infusion. Cardiac arrhythmias were frequent at or after the end of the initial hypotension. In the last two animals subsequent blood pressure records were unreliable, although the hypertension due to epileptic seizures was recorded. In four of the seven animals a sharp fall in blood pressure and in heart rate occurred at the end of subsequent periods of cyanide infusion and coincided with apnoea in three. In one of these four animals (no. 11) the last infusion of cyanide was termi- 


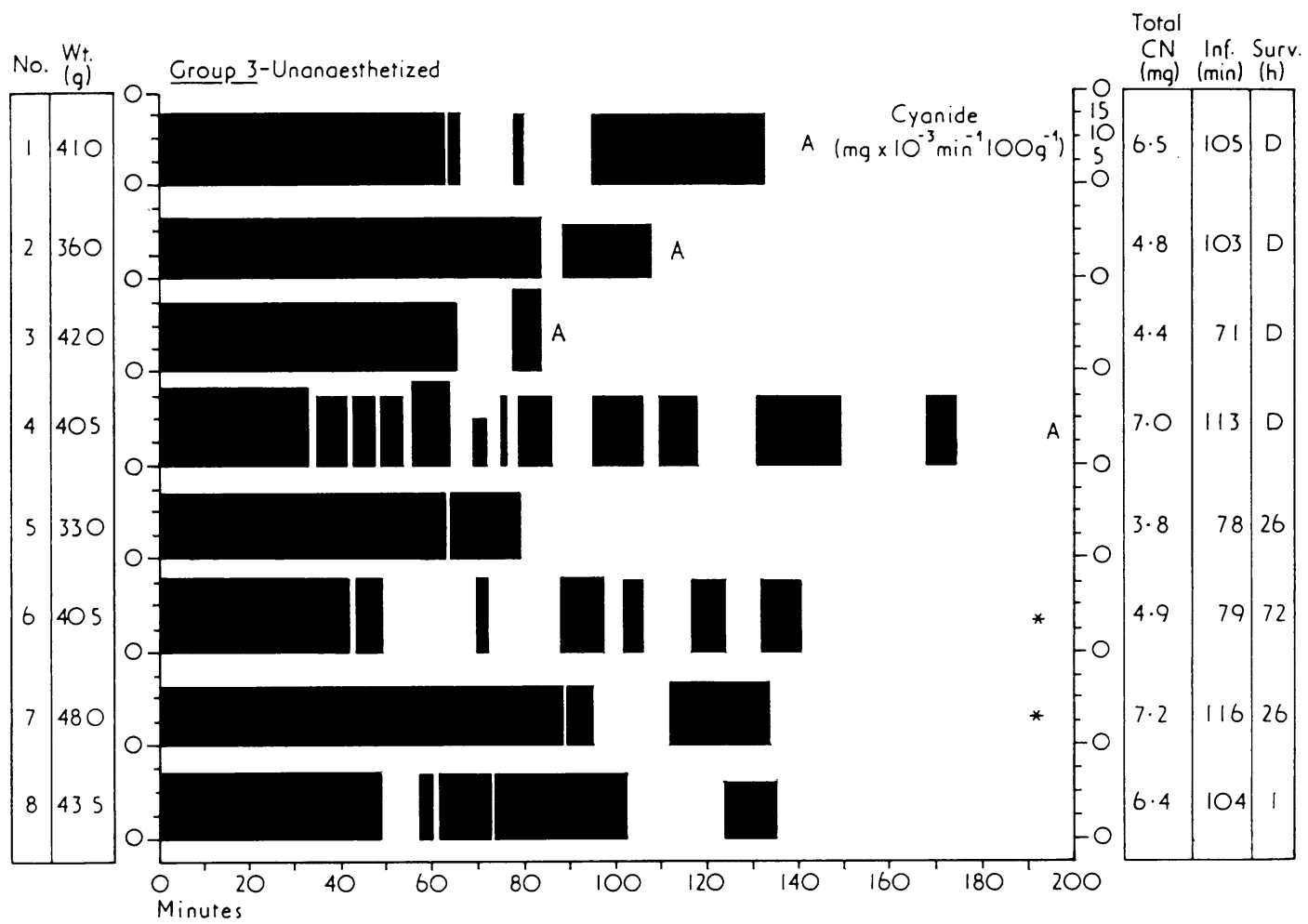

FIG. 2, Group 3. Showing data as in Fig. 1. D=death due to cardiorespiratory failure, brain not examined.

nated because of the coincidence of apnoea, cardiac arrhythmia, and a fall in mean blood pressure to about $20 \mathrm{mmHg}$.

GROUP 3 (EIGHT ANIMALS) The body weights. periods, and rates of cyanide infusion. total dose of cyanide, and the incidence of apnoea and of brain damage are given in Fig. 2.

While the range of total cyanide infused was similar to that in group 3 . the consequences, as judged by survival alone, were different. Thus, in spite of attempts at resuscitation. four animals (nos. 1. 2, 3,4) died of cardiorespiratory failure 83 to 200 minutes from the start of cyanide infusion and before perfusion-fixation of the brains could be carried out. so that the brains were not examined. In the other four animals, perfusion-fixation was carried out deliberately from 60 minutes to three days after the end of cyanide infusion.

Apnoea occurred during the infusion of cyanide in one animal (no. 8) at 80 minutes from the start. It was a terminal event in two animals (nos. 3. 4).

In all eight animals, respiratory rates rose by $40-103^{\circ}$, during the initial infusion of cyanide and there was up to a threefold increase in the depth of respiration as judged by pen excursion. In seven animals, respiration was reduced in rate and was irregular at or near the end of cyanide infusion and of physiological recording in the three animals that recovered consciousness and were returned to their cages (nos. 2, 4, 7).

Tetany occurred in each animal at 15 to 30 minutes from the start of cyanide infusion and outlasted the period of infusion by up to 30 minutes and was always accompanied by myoclonus. This was very severe in four animals (nos. 1, 4, 6, 7) and took the form of synchronous contractions of the whole body musculature. Myoclonus of this type was less frequent in 


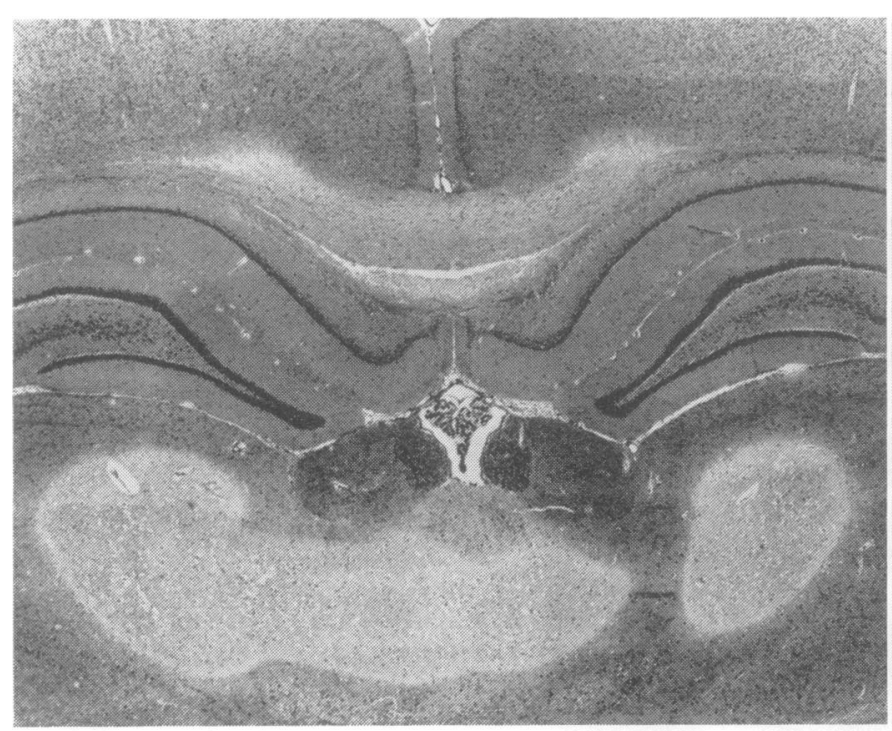

(a)

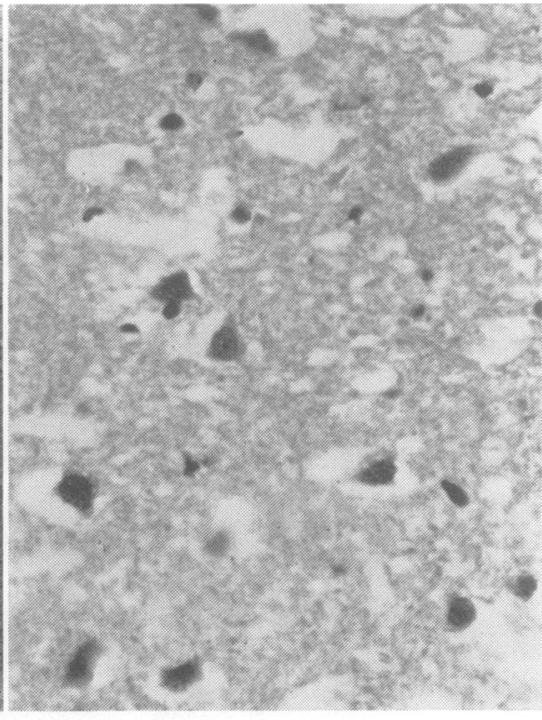

(b)

FIG. 3 (a) Group 2, no. 11. Survival 27 h. Coronal section showing pallor of myelin staining in corpus callosun and sharply defined areas of ischaemic necrosis in thalami. Paraffin; haematoxylin and eosin ( $H$ and $E \stackrel{2}{\circ}$ $\times 15$. (b) Animal as in (a). Thalamus showing homogenizing cell change. Paraffin; $H$ and $E, \times 360$.

three animals (nos. 2, 3, 5) and was restricted to limb muscles in one animal (no. 8). Myoclonus as an accompaniment of tetany was the major muscular activity in each animal. Distinguishing between serial myoclonic activity as a culmination of an episode of tetany and tonic-clonic epileptic seizures was more difficult than in the animals of group 2 .

The duration of whole-body myoclonus appeared to be an important cause of the cardiorespiratory collapse that occurred at 85 to 200 minutes after the start of cyanide infusion in four animals (nos. 1, 3, 5, 6).

Control heart rates were in the range 340 to $480 /$ min (mean $405 / \mathrm{min}$ ). In all eight animals, heart rates rose by $10-32 \%$ above control levels during the first infusion of cyanide and always decreased before its end. Thereafter, heart rates varied widely and usually fell appreciably towards the end of subsequent infusions of cyanide and rose during epileptic seizures and periods of myoclonus.

Neuropathology

Macroscopic appearances Slight to moderate brain swelling as judged by herniation of the inferior cerebellar vermis was seen in sever animals of group 2, including all four with oे microscopic alterations (nos. 5, 7, 8, 11) and also in three (nos. 3, 6, 9) that were microscopically normal. It was also seen in one (no. 7) of the two animals of group 3 showing microscopic alterations. Appearances were normal in slices of the 15 brains examined.

Microscopic appearances Neuropathological alterations were seen in six animals; in four of group 2 (nos. 5, 7, 8, 11) and in two of group 3 (nos. 6, 7). There was white matter damage in all six and additional damage in grey matter in only one, no. 11 of group 2 . In this animal (survival, $27 \mathrm{~h}$ ) typical homogenizing cell change was restricted to a sharply circumscribed lesion involving each thalamus and corpus striatum (Fig. 3a). It began posteriorly at the level of the posterior commissure as more or less symmetrical areas in the centre of each thalamus. O Further forward these became confluent across 0 the mid-line giving a dumb-bell profile. At the $\underset{\omega}{\widetilde{\omega}}$ level of the anterior nuclear complexes the 


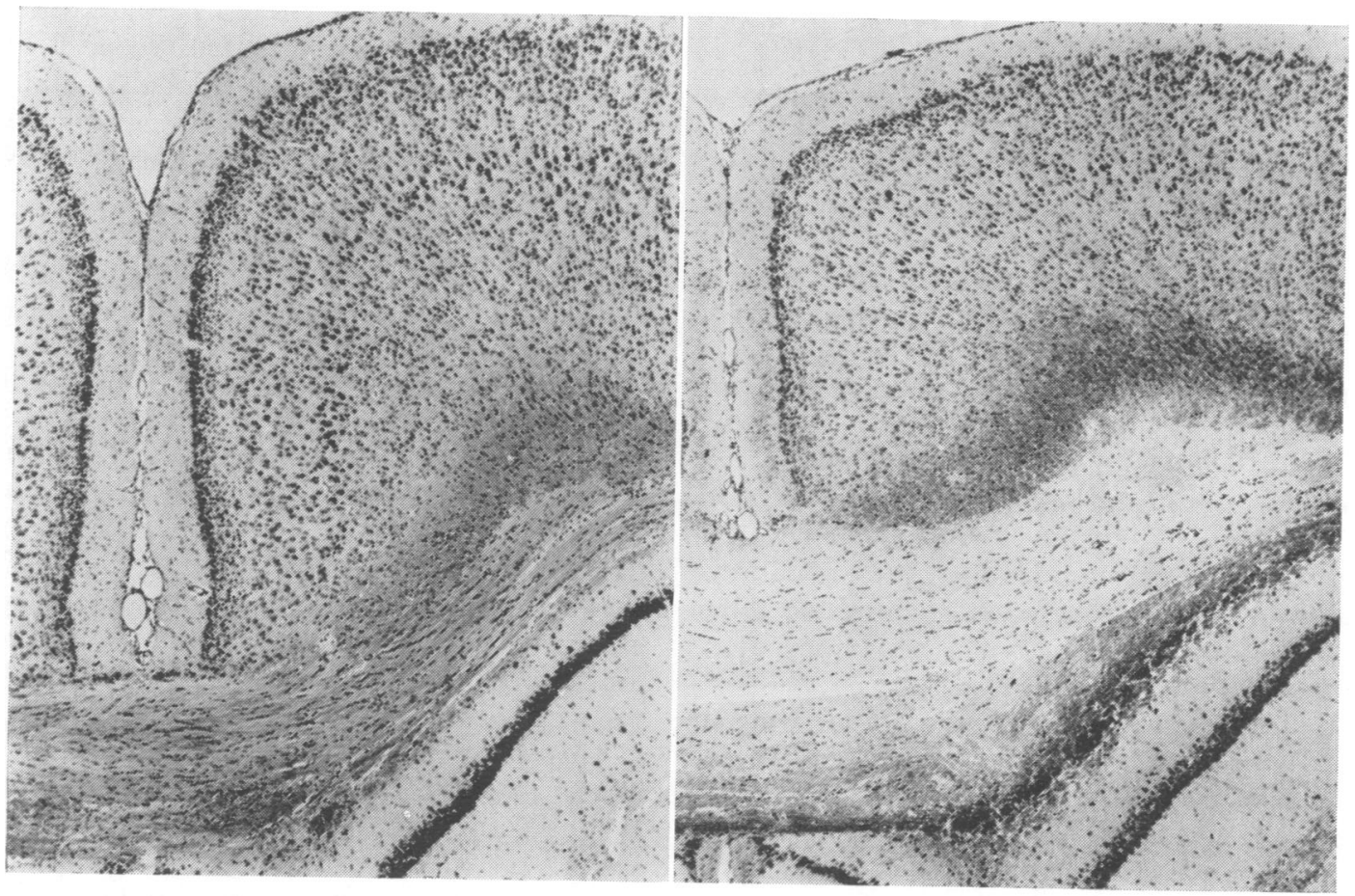

(a)

(b)

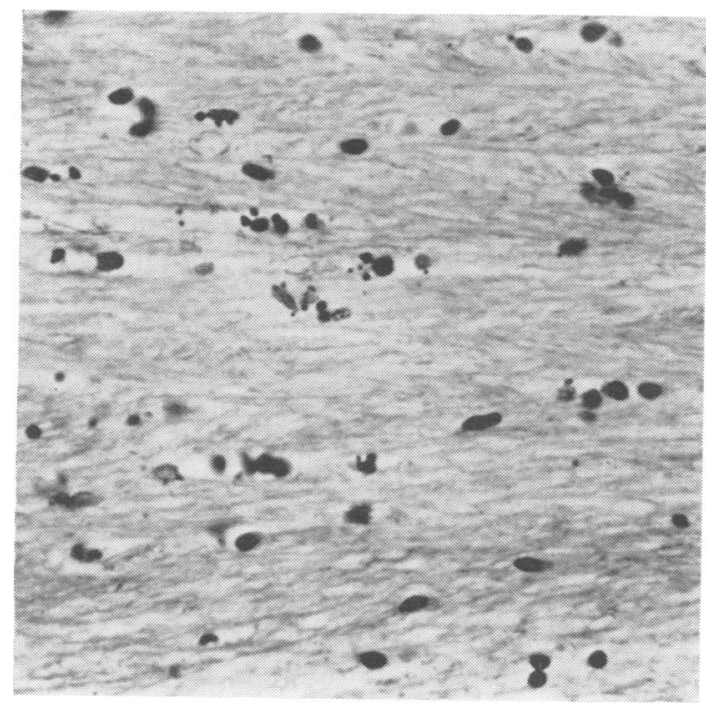

(c) lesion again became bilateral and died out in the posterior third of each corpus striatum.

Within the lesion the tissue appeared spongy as a result of numerous dilated perineuronal and perivascular spaces. Many of the former contained neurones with shrunken darkly-stained nuclei surrounded by eosinophilic cytoplasm devoid of Nissl substance (Fig. 3b). Fine incrustations were seen around a minority of these neurones. There were no appreciable

FIG. 4 (a) Control rat. Coronal section showing normal myelin staining in corpus callosum. Paraffin; Luxol fast blue and cresyl violet, $\times 40$. (b) Group 2, no. 11. Coronal section showing pallor of myelin staining in corpus callosum. Paraffin; Luxol fast blue and cresyl violet, $\times 40$. (c) Group 2, no. 5 . Coronal section of corpus callosum showing shrinkage and hyperchromasia of nuclei of interfascicular oligodendrocytes, some of which are fragmented. Paraffin; Luxol fast blue and cresyl violet, $\times 470$. 
alterations in astrocytes, microglia, or blood vessels.

In the six animals showing alterations in white matter, survival was $25-28 \mathrm{~h}$ in five, and three days in one (group 3, no. 6). In all, the corpus callosum was the only structure affected (Fig. 4a, b). In one animal (group 2, no. 8) myelin damage was confined to the posterior third. In the other five, myelin damage extended as far anteriorly as the level of the septal complex but always decreasing from behind forwards. After a survival of 25-28 h (five animals) sections in the coronal plane showed that narrow ventral and sometimes dorsal portions of the corpus callosum were spared as well as the hippocampal commissure and each fornix. Pallor of myelin staining decreased on either side of the mid-line within a maximum lateral extent of about $2.5 \mathrm{~mm}$.

In the regions of myelin pallor, myelin sheaths were beaded and irregular but the axis cylinders appeared normal. While the astrocytes were unaltered, the interfascicular oligodendrocytes showed alterations consisting of shrinkage and hyperchromasia of nuclei, a proportion of which had broken down into dark-staining irregular fragments (Fig. 4c). Lipid phagocytes were not seen.

After a survival of three days (group 3, no. 6) myelin pallor was marked and the sheaths were beaded or ballooned and separated. There was an appreciable reduction in the numbers of oligodendrocytes and the distribution of those that remained was disorganized and a few nuclear fragments were seen. There were no lipid phagocytes and no reactive microglia. Large vesicular astrocytic nuclei were a prominent feature and the mitotic figures observed were probably in such cells.

\section{DISCUSSION}

As the purpose of this study was to decide if pure histotoxic hypoxia could produce classical ischaemic cell change in the neurones of spontaneously breathing rats, sodium cyanide was administered by intravenous infusion so that the dose rate could be modified according to physiological criteria. The animals of group 1 were used to define a rate of infusion that would just avert apnoea in a majority of animals. Even so, this rate of infusion had to be reduced and/or interrupted in the anaesthetized (group 2) and in the conscious restrained (group 3) animals because of impaired respiratory and cardiovascular functions. In fact, a steady physiological state was never attained in any animal.

Brain damage was seen in six of the 19 animals of groups 2 and 3. The white matter was involved in all six, but neurones additionally in only one (group 2 , no. 11, survival $27 \mathrm{~h}$ ). In this animal, the homogenizing stage of the ischaemic process was seen in portions of the basal ganglia. As the earliest stages of ischaemic cell change are readily recognizable in brains fixed by in vivo perfusion immediately after a hypoxic stress (Brown and Brierley, 1968, 1973), there was no difficulty in deciding that such changes were absent in the brains of those animals in group 2 in which survival was $1 \frac{3}{4}$ to three hours.

The distribution of the altered neurones in the single animal of group 2 was unusual in tha? they were confined to a dumb-bell shaped? volume of tissue in the diencephalon while $\rightarrow$ the cerebral cortex, hippocampi, and cerebellum $\frac{1}{8}$ were normal. In this animal, epileptic seizureso were frequent and the infusion of cyanide had to be terminated because of the coincidence of apnoea, cardiac arrhythmia, and a fall in mean blood pressure to about $20 \mathrm{mmHg}$. While cerebral blood flow would have fallen considerably at this time, the restriction of ischaemic damage to the diencephalon suggests that there may have been a simultaneous rise in central venous pressure. This suggestion is supported by the observation of ischaemic cell change in the anterior diencephalon of a Rhesus monkey that had received sodium cyanide by intravenous infusion. This was terminated when apnoea coincided with a fall in blood pressure, bradycardia, and a rise in central venous pressure (recorded from the superior longitudinal sinus) to about $18 \mathrm{mmHg}$ (Brierley, Prior, Brown, and Calverley, unpublished observations). In the single animal of the present series, the localized neuronal damage must be attributed to the additional secondary effects of cyanide upon the circulation, although these can be defined only in terms of heart rate and blood pressure.

Damage in the grey matter of the rat brain as a consequence of cyanide intoxication has been 
described by previous workers. Hicks (1950) described damage ranging from '... necrosis of scattered neurones to complete dissolution of a region not unlike that seen in infarction' ( $p$. 119). It was seen in cerebral cortex, striatum, and substantia nigra. The aim of that study was '... to produce the maximal damage possible just short of killing the animal immediately .... Sodium .cyanide was given intraperitoneally, severe convulsions occurred within a minute and were followed by coma lasting up to 30 minutes. Apnoea sometimes followed a convulsion and, as soon as there was evidence of recovery, another injection was given.

Levine and Stypulkowski (1959) administered hydrocyanic acid (HCN) to rats by inhalation for periods of 20 to 45 minutes. Grey matter damage was seen in the striatum, pyriform cortex, and the paramedian portions of the neocortex but only after severe intoxication (stage 4). It was not appreciated that cortical damage was concentrated along the boundary zone between anterior and middle cerebral arterial territories and was therefore due to some period of reduced cerebral perfusion.

Intravenous injection of potassium cyanide (Levine and Wenk, 1959) produced neuropathological alterations identical in type, localization, and extent with those seen after inhalation of hydrocyanic acid, so that, in the rat, brain damage can follow administration of cyanide by several routes. However, the physiological status of the animals during and after the period of acute intoxication has not been defined in previous studies.

The animals of the present series, and in particular those of group 2, demonstrated the physiological effects of sub-lethal and lethal cyanide intoxication. Hyperventilation, the earliest effect, was seen in all members of the three groups. In those of group 2, arterial $\mathrm{pO}_{2}$ rose from a mean of $84 \mathrm{mmHg}$ to a mean of 126 $\mathrm{mmHg}$, while arterial $\mathrm{pCO}_{2}$ fell from a mean of $50 \mathrm{mmHg}$ to a mean of $14 \mathrm{mmHg}$. The latter level is a consequence of hyperventilation and also the inhibition of aerobic $\mathrm{CO}_{2}$ production by cyanide. Arterial $\mathrm{pH}$ rose from a mean of 7.394 to a mean maximum of 7.613. The ability of mechanical ventilation, per se, to cause brain hypoxia in cats and monkeys was demonstrated by Meyer and Gotoh (1960). A reduced blood carbon dioxide tension led to a fall in cortical oxygen tension through the medium of vasoconstriction. Granholm et al. (1969), using mechanical ventilation in the cat and rat, showed that when arterial $\mathrm{pCO}_{2}$ was less than 20-25 $\mathrm{mmHg}$ there was a progressive increase in lactate and in the lactate-pyruvate ratio in brain tissue and in cerebrospinal fluid, which they ascribed to brain hypoxia. Miller and Ledingham (1971), in the dog, also showed that when mechanical ventilation had reduced a.pCO $\mathrm{CO}_{2}$ to less than $20 \mathrm{mmHg}$, cerebral blood flow had fallen by $39 \%$. While there is much evidence to show that mechanical ventilation can lead to reduced brain blood flow and brain hypoxia, it must be emphasized that, in the present investigation, hyperventilation was spontaneous and mechanical ventilation was employed only when apnoea occurred. Even so, the low levels of a. $\mathrm{pCO}_{2}$ (minimum $14 \mathrm{mmHg}$ ) most probably led to vasoconstriction and therefore to some reduction in brain blood flow. The latter may have outlasted the period of cyanide infusion in view of the delayed rise in a. $\mathrm{pCO}_{2}$.

The reduction in arterial $\mathrm{pCO}_{2}$ also shifts the dissociation curve of oxyhaemoglobin to the left, so that for a particular saturation of blood leaving the lungs a reduced oxygen pressure gradient between blood and tissue is superimposed upon the histotoxic effects of cyanide.

The persistence of hyperventilation after the end of cyanide infusion in 10 animals was probably due to continuing chemoreceptor stimulation by cyanide, the known continuation of a low apH or both.

The close temporal relationship between the peak values for arterial $\mathrm{pH}$ and the onset of tetany appears to endorse the view of Edmondson et al. (1975) that tetany appearing during hypocapnoeic alkalosis may be due to a raised apH combined with the reduction in circulating $\mathrm{Ca}^{2}+$ that is a direct yet relatively minor consequence of alkalosis.

In all the animals of group 2, the fall in arterial $\mathrm{pH}$ following the peak values (10 to 73 minutes after the start of cyanide infusion), occurred in spite of sustained hypocapnia. This fall in apH must be attributed to the production of lactate in the body as well as in the brain (Olsen and Klein, 1947; McIlwain, 1966). The shift to anaerobic metabolism induced by 
cyanide would be increased by epileptic activity which, by reducing brain glycogen, glucose, and ATP would raise the blood levels of lactate, ADP, and inorganic phosphate (Albaum et al., 1946). The fall in arterial $\mathrm{pH}$ was usually associated with the appearance of cardiac arrhythmias and with systemic hypotension and it always preceded major deterioration in the EEG. In the seven animals in which the EEG became isoelectric (Table 2) the fall in apH began five to 45 minutes earlier and was from $0.04-0.49 \mathrm{pH}$ units. It was greatest in animal no. 11 of group 2 , in which neurones as well as white matter were damaged.

It is to be noted that the secondary effects of cyanide on cardiac and respiratory functions were present to some extent in all 19 animals of groups 2 and 3. They were a cause of early death in four of the latter group. Nevertheless, brain damage was seen in only six animals and involved white matter in all. It was not possible, however, to relate white matter damage to the total dose of cyanide, the duration of its infusion, or to the incidence and extent of its secondary effects. As white matter damage was seen only after a survival of 25 hours and in association with fragmentation of the nuclei of oligodendrocytes, it was not possible to decide which was the earlier of the two alterations.

The secondary effects of cyanide on respiration and particularly on the circulation attained their maxima in animal no. 11 of group 2. As this was the only animal in which neurones were damaged, it must be concluded that, in the intact and spontaneously breathing rat, the entity of a hypoxic neuronal damage of a purely histotoxic type does not exist.

\section{REFERENCES}

Albaum, H. G., Tepperman, J., and Bodansky, O. (1946). The in vivo inactivation by cyanide of brain cytochrome oxidase and its effect on glycolysis and on the high energy phosphorus compounds in brain. Journal of Biological Chemistry, 164, 45-51.

Brierley, J. B. (1973). Pathology of cerebral ischemia. In Cerebral Vascular Diseases, Eighth Conference, pp. 59-75. Edited by Fletcher H. McDowell and Robert W. Brennan. Grune and Stratton: New York.

Brown, A. W., and Brierley, J. B. (1968). The nature, distribution and earliest stages of anoxic-ischaemic nerve cell damage in the rat brain as defined by the optical microscope. British Journal of Experimental Pathology, 49, 87106.

Brown, A. W., and Brierley, J. B. (1973). The earliest alterations in rat neurones after anoxia-ischaemia. Acta Neuropathologica (Berl.), 23, 9-22.

Edmondson, J. W., Brashear, R. E., and Li, T-K. (1975). Tetany: quantitative interrelationships between calcium and alkalosis. American Journal of Physiology, 228, 10821086.

Granholm, L., Lukjanova, L., and Siesjö, B. K. (1969). The effect of marked hyperventilation upon tissue levels of NADH, lactate, pyruvate, phosphocreatine and adenosine phosphates of rat brain. Acta Physiologica Scandinavica, 77, 179-190.

Hicks, S. P. (1950). Brain metabolism in vivo. 1. The distribution of lesions caused by cyanide poisoning, insulin hypoglycemia, asphyxia in nitrogen and fluoro-acetate poisoning in rats. Archives of Pathology, 49, 111-137.

Levine, S., and Stypulkowski, W. (1959). Experimentad cyanide encephalopathy. Archives of Pathology, 67, 306용 323.

Levine, S., and Wenk, E. J. (1959). Cyanide encephalopath $\bar{\Phi}$ produced by intravenous route. Journal of Nervous and Mental Disease, 129, 302-305.

Mcllwain, H. (1966). Biochemistry and the Central Nervot System, pp. 39-41. Churchill: London.

Meyer, A. (1963). Intoxications. In Greenfield's Neuropath ology, pp. 235-287. Edited by W. Blackwood, W. H. McMenemey, A. Meyer, R. M. Norman, and Dorothy S. Russell. Arnold: London.

Meyer, J. S., and Gotoh, F. (1960). Metabolic and electroencephalographic effects of hyperventilation. Archives of Neurology, 3, 539-552.

Miller, J. D., and Ledingham, I. McA. (1971). Reduction of increased intracranial pressure. Comparison between hyperbaric oxygen and hyperventilation. Archives of Neurology, 24, 210-216.

Olsen, N. S., and Klein, J. R. (1947). Effect of cyanide on the concentration of lactate and phosphates in brain. Journal of Biological Chemistry, 167, 739-746.

Stoner, H. B. (1971). Effect of injury on shivering thermogenesis in the rat. Journal of Physiology, 214, 599-615.

Van Liere, E. J., and Stickney, J. C. (1963). Hypoxia, p. 28. University of Chicago Press: Chicago. 